\title{
Inspeção predial nas dependências da Escola Estadual Professor Rafael Magalhães de Itajubá-MG
}

\author{
Building inspection in the premisses of the State School Professor Rafael Magalhães in Itajubá- \\ MG \\ Inspección de edificios en las instalaciones de la Escuela Estatal Professor Rafael Magalhães de \\ Itajubá-MG
}

Recebido: 30/03/2021 | Revisado: 16/04/2021 | Aceito: 26/04/2021 | Publicado: 10/05/2021

\author{
Matheus David Guimarães Barbedo \\ ORCID: https://orcid.org/0000-0001-9261-3696 \\ Universidade Federal de Itajubá, Brasil \\ E-mail: matheusdgb@hotmail.com \\ Thayná Antônia da Silva Gonçalves \\ ORCID: https://orcid.org/0000-0001-8299-2151 \\ Universidade Federal de Itajubá, Brasil \\ E-mail: thayna.sgoncalves@hotmail.com
}

\begin{abstract}
Resumo
Este trabalho consiste em realizar a inspeção predial na Escola Estadual Professor Rafael Magalhães de Itajubá-MG ao qual identificou as patologias existentes como: fissuras, trincas, rachaduras, mofo, bolor, fiação elétrica exposta e com emendas, dentre outras e em seguida foi elaborado um laudo de inspeção predial baseado na norma do IBAPE (Instituto Brasileiro de Avaliações e Periciais de Engenharia) com o diagnóstico e prognóstico de cada manifestação patológica, e com o intuito de recuperar a estrutura gerou-se uma tabela com uma lista de prioridades de intervenção na edificação. Através da análise do laudo conclui-se que é necessário intervir com urgência na estrutura com uma manutenção corretiva, pois a mesma apresenta patologias que colocam em risco a integridade física das pessoas que ali convivem, além de se tratar de uma edificação de ensino que deve ter um ambiente saudável e seguro. Palavras-chave: Patologias; Inspeção predial; Diagnóstico; Prognóstico; Intervir.
\end{abstract}

\begin{abstract}
This work consists in carrying out the building inspection in the State School Professor Rafael Magalhães of ItajubáMG to which identified the existing pathologies such as: cracks, fissures, cracks, mold, mildew, exposed and spliced electrical wiring, among others, and then a building inspection report was prepared based on the IBAPE (Brazilian Institute of Evaluations and Expert Engineering) standard with the diagnosis and prognosis of each pathological manifestation, and in order to recover the structure a table was generated with a list of priorities for intervention in the building. Through the analysis of the report it was concluded that it is necessary to urgently intervene in the structure with a corrective maintenance, because it presents pathologies that put at risk the physical integrity of the people who live there, besides being an educational building that should have a healthy and safe environment.
\end{abstract} Keywords: Pathologies; Building inspection; Diagnosis; Prognosis; Intervention.

\section{Resumen}

Este trabajo consiste en la realización de la inspección del edificio en la Escuela Estatal Profesor Rafael Magalhães de Itajubá-MG a la que identificó las patologías existentes como: grietas, fisuras, grietas, moho, cableado eléctrico expuesto y con enmiendas, entre otros y luego se preparó un informe de inspección del edificio basado en la norma IBAPE (Instituto Brasileño de Evaluaciones e Ingeniería de Expertos) con el diagnóstico y pronóstico de cada manifestación patológica, y con el fin de recuperar la estructura se generó una tabla con una lista de prioridades para la intervención en el edificio. A través del análisis del informe se concluyó que es necesario intervenir urgentemente en la estructura con un mantenimiento correctivo, ya que presenta patologías que ponen en riesgo la integridad física de las personas que la habitan, además de ser un edificio educativo que debe tener un ambiente sano y seguro. Palabras clave: Patologías; Inspección de edificios; Diagnóstico; Pronóstico; Intervención. 


\section{Introdução}

Desde o inicio das civilizações o homem tem a atividade da construção, e seus métodos vem passando de geração para geração. Com o passar do tempo, houve um aprimoramento de algumas práticas, assim incorporando novos conhecimentos nesta área. O desenvolvimento em ritmo acelerado da construção civil para atender uma demanda crescente por edificações sejam elas laborais, industriais ou habitacionais, impulsionado pela própria modernização da sociedade, promoveu um grande salto científico e tecnológico e com isso surgiu à necessidade de atender as demandas de diversas edificações com um processo construtivo mais acelerado, que atenda curtos prazos e que tenha um alto custo benefício, ou seja, os empreendedores do ramo da construção civil buscam rapidez e lucro. (Ambrosio, 2004).

Segundo Souza e Ripper (1998), o ramo da Engenharia Civil que se ocupa do estudo das origens, formas de manifestação, consequências e mecanismos de ocorrência de falhas e dos sistemas de degradação de estruturas constitui-se de forma geral por patologia das estruturas. Define-se por patologia a parte da engenharia que estuda os sintomas, mecanismos, as causas e as origens dos defeitos das construções civis, além da solução destes problemas, inclusive os oriundos do envelhecimento natural (Degussa, 2008; Rios et al., 2017; Torres e Silva, 2015; França et al., 2011).

De acordo com Helene (2003), ao se projetar e construir uma edificação é necessário prever que ela perderá desempenho parcial ou total ao sofrer com os malefícios das patologias, pois os materiais de construção civil sofrem desgaste devido ao contato com os mecanismos de deterioração de estruturas do meio ambiente. Para Silva (2011), uma manifestação patológica é a expressão mais decorrente de um agente de degradação, já a patologia é uma ciência formada por um conjunto de fundamentos ao qual visa explicar o mecanismo e o motivo da ocorrência de determinada manifestação patológica. Desta forma fica claro que patologia é um termo mais abundante do que manifestação patológica, pois um conjunto de manifestações patológicas pode constituir uma patologia.

As manifestações patológicas são provocadas por falhas que acontecem na execução de uma ou mais atividades do processo de construção civil (Tutikian e Pacheco, 2013; Almeida, 2008). Segundo Vieira (2016), Pina (2013) e Lima (2005), muitas patologias das edificações demonstram inúmeros indícios que possibilitam a sua identificação, principio, motivos do seu surgimento além das futuras consequências se não forem aplicadas soluções cabíveis.

De acordo com Silva (2011) têm surgido com o intuito de efetuar parecer das patologias nas edificações, técnicas para captar manifestações patológicas como ensaios destrutivos e não destrutivos.

Segundo Tutikian e Pacheco (2013) para saber qual atitude tomar diante de manifestações patológicas e poder agir de forma eficiente, proporcionando uma recuperação adequada ao tipo de doença apresentada se faz necessário conhecer a real situação da anomalia, por meio dos fatores que ocasionam a manifestação patológica na edificação. De acordo com Helene (1988) e Torres e Silva (2015), a partir de uma análise com uma visão ampla, as patologias das edificações têm basicamente como razão a dilatação e contração devido à mudança de temperaturas, sobrecargas, umidade e seus meios, materiais fora da especificação técnica e erros de execução.

Correndo o risco de causar acidentes de alta gravidade com vitimas fatais, além de prejuízos financeiros, as anomalias patológicas quase sempre se iniciam em falhas de projeto, detalhamento, execução e dimensionamento (Cunha et al., 1996; Alves et al., 2015).

Para Azevedo e Guerra (2009), as manifestações patológicas não aparecem aleatoriamente, sempre existe alguma patologia que a fez surgir, e conhecer as suas causas é o principal fator contribuinte para seu diagnóstico e tratamento.

O presente artigo tem como objetivo avaliar o estado de uma edificação escolar de gestão pública através de uma inspeção predial. 


\section{Metodologia}

A metodologia utilizada no trabalho será a de Dagostin (2010) que menciona as tabelas de GUT (Gravidade, Urgência e Tendência), que auxiliam nas escolhas das prioridades para manutenção onde as análises são colocadas de forma decrescente quanto ao grau de risco das anomalias e falhas, de maneira que cada anomalia ou falha encontrada tem um peso como mostra às Tabelas 1,2 e 3.

Tabela 1 - Gravidade X Pesos.

\begin{tabular}{l|l|c}
\hline \multicolumn{1}{c|}{ Grau } & \multicolumn{1}{|c}{ Gravidade } & Peso \\
\hline Total & Perda de vidas humanas, do meio ambiente ou do próprio edifício. & 5 \\
\hline Alta & Ferimentos a pessoas, danos ao meio ambiente ou edifício. & 4 \\
\hline Média & Desconfortos, deterioração ao meio ambiente e edifício. & 3 \\
\hline Baixa & Pequenos incômodos & 2 \\
\hline Nenhuma & & 1 \\
\hline
\end{tabular}

Fonte: Técnicas de Inspeção e Manutenção Predial (Gomide, 2006).

Tabela 2 - Urgência X Pesos.

\begin{tabular}{l|l|c}
\hline \multicolumn{1}{c|}{ Grau } & \multicolumn{1}{c|}{ Urgência } & Peso \\
\hline Total & Evento em ocorrência. & 5 \\
\hline Alta & Evento prestes a ocorrer. & 4 \\
\hline Média & Evento prognosticado para breve. & 3 \\
\hline Baixa & Evento prognosticado para adiante. & 2 \\
\hline Nenhuma & Evento imprevisto/pode não ocorrer. & 1 \\
\hline
\end{tabular}

Fonte: Técnicas de Inspeção e Manutenção Predial (Gomide, 2006)

Tabela 3 - Tendência X Pesos.

\begin{tabular}{l|l|c}
\hline \multicolumn{1}{c|}{ Grau } & \multicolumn{1}{c|}{ Tendência } & Peso \\
\hline Total & Evolução imediata. & 5 \\
\hline Alta & Evolução em curto prazo. & 4 \\
\hline Média & Evolução em prazo médio. & 3 \\
\hline Baixa & Evolução em longo prazo. & 2 \\
\hline Nenhuma & Não vai evoluir & 1 \\
\hline
\end{tabular}

Fonte: Técnicas de Inspeção e Manutenção Predial (Gomide, 2006) 


\section{Resultados e Discussão}

Figura 1 - Rachaduras e trincas no pilar e na viga.

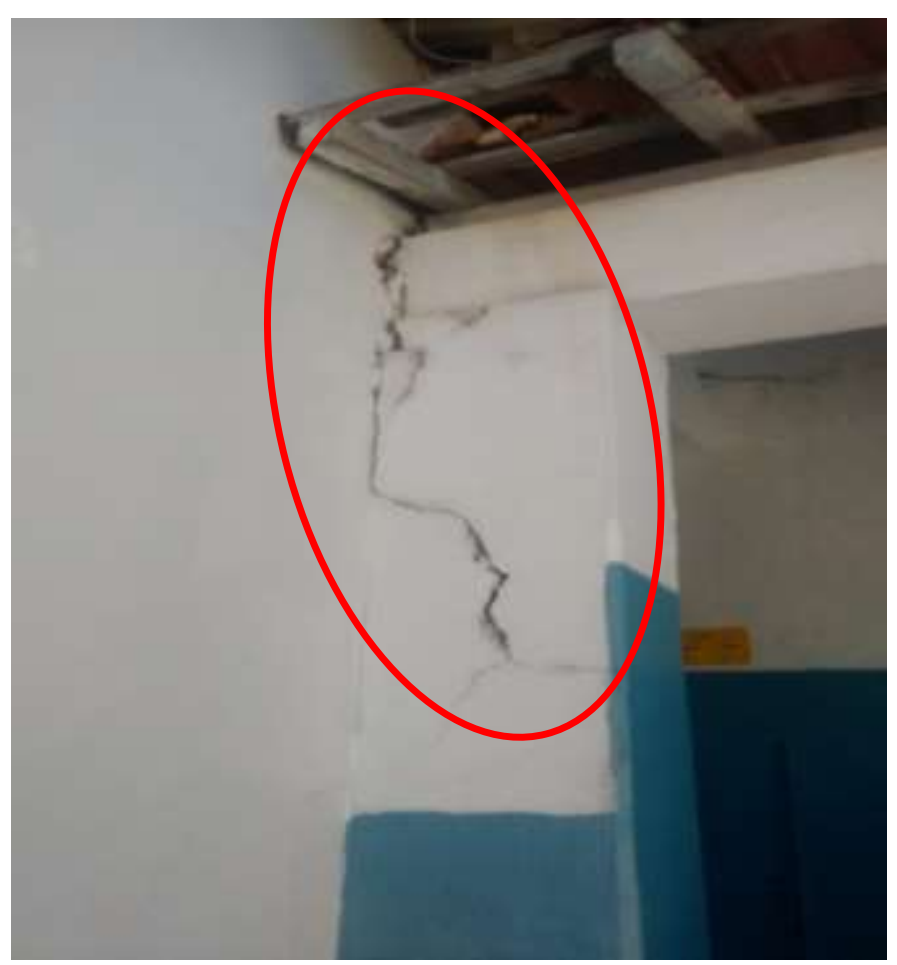

Fonte: Autores (2018).

A Figura 1 mostra as trincas e rachaduras em uma viga e em um pilar do corredor coberto de acesso as salas de aula e a quadra.

Tabela 4 - Avaliação das rachaduras e trincas no pilar e na viga.

\begin{tabular}{|c|c|}
\hline Justificativa da ocorrência & Orientação técnica \\
\hline $\begin{array}{l}\text { As trincas e rachaduras foram provocadas por atuação de } \\
\text { sobrecargas, movimentação da estrutura, variações térmicas e } \\
\text { umidade, recalque diferencial das fundações. }\end{array}$ & $\begin{array}{l}\text { Abrir um sulco sobre a fissura, } \\
\text { remover o acabamento,e a ferrugem da } \\
\text { armadura se for o caso, limpar e } \\
\text { molhar a superficie, aplicar o reparo } \\
\text { estrutural e impermeabilizar. }\end{array}$ \\
\hline Tendência & Gravidade \\
\hline 5 & 125 \\
\hline
\end{tabular}

Fonte: Autores (2018).

A Tabela 4 indicou a pontuação máxima possível de ser obtida e como conseqüência disso coloca a vida dos alunos e funcionários em risco devido ao possível desabamento da estrutura. 
Figura 2 - Rachadura no muro e no pilar.

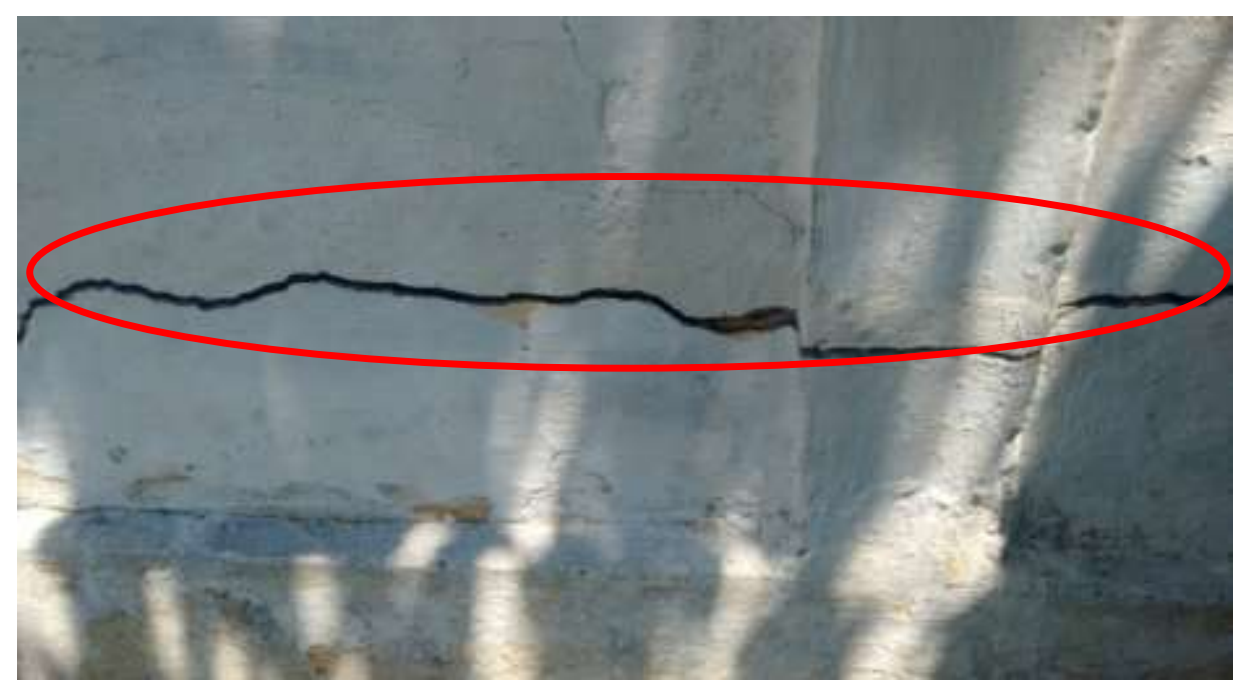

Fonte: Autores (2018).

A Figura 2 mostra uma rachadura no muro e no pilar de sustentação do muro da divisa lateral da escola com a casa vizinha.

Tabela 5 - Avaliação da rachadura na alvenaria e no pilar.

\begin{tabular}{|c|c|}
\hline Justificativa da ocorrência & Orientação técnica \\
\hline $\begin{array}{l}\text { A rachadura foi provocada por atuação de sobrecargas, } \\
\text { movimentação da estrutura, variações térmicas e umidade, } \\
\text { recalque diferencial das fundações. }\end{array}$ & $\begin{array}{l}\text { Para a rachadura na parede abrir uma } \\
\text { abertura em "V", em seguida limpar a } \\
\text { superfície e aplicar preparador de paredes e } \\
\text { depois preencher a fenda com sela trinca, } \\
\text { colocar uma tela de poliéster e fechar com } \\
\text { argamassa. } \\
\text { Para a rachadura no pilar abrir um sulco } \\
\text { sobre a fissura, remover o acabamento, e } \\
\text { a ferrugem da armadura se for o caso, } \\
\text { limpar e molhar a superficie, aplicar o } \\
\text { reparo estrutural e impermeabilizar. }\end{array}$ \\
\hline Tendência & Gravidade \\
\hline 5 & 125 \\
\hline
\end{tabular}

Fonte: Autores (2018).

A Tabela 5 indicou a pontuação máxima possível de ser obtida e como conseqüência disso coloca a vida dos alunos e funcionários em risco devido ao possível desabamento do muro. 
Figura 3 - Ação dos cupins nas peças de madeira da cobertura.

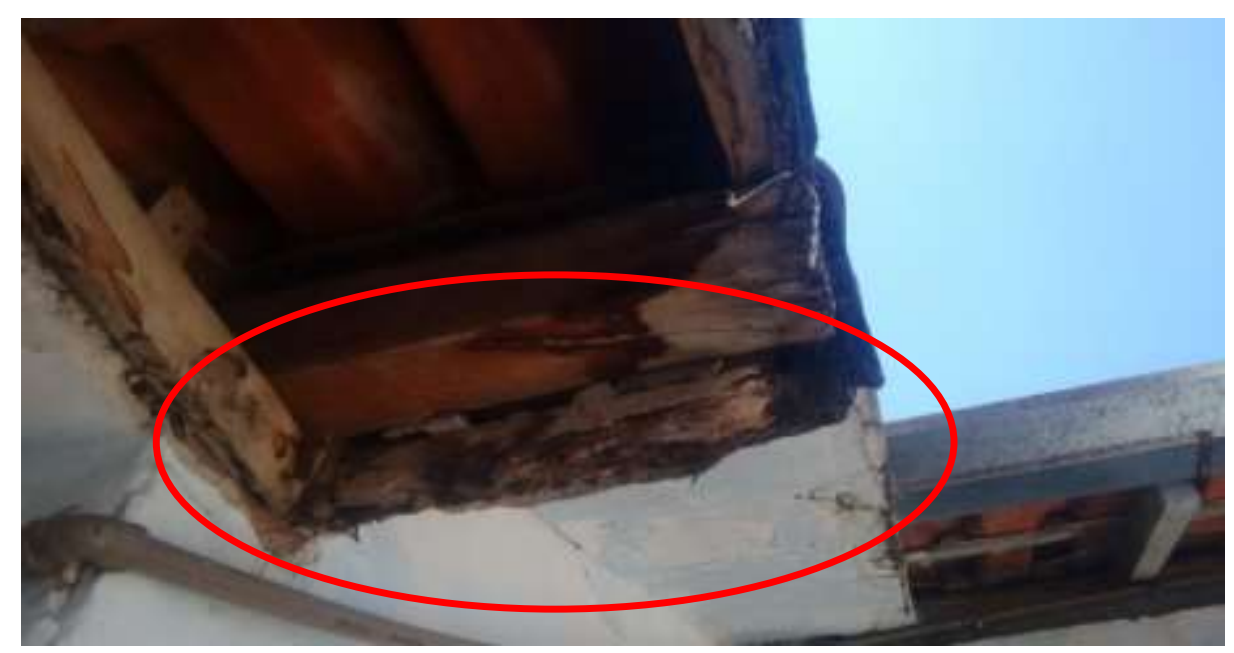

Fonte: Autores (2018).

A Figura 3 mostra a degradação das peças de madeira que sustentam a cobertura, ocasionadas pela ação dos cupins de madeira seca.

Tabela 6 - Avaliação da ação dos Cupins nas peças de madeira.

\begin{tabular}{|c|c|}
\hline Justificativa da ocorrência & Orientação técnica \\
\hline $\begin{array}{l}\text { Os cupins são oriundos de cupinzeiros e são atraídos } \\
\text { pela luz das residências, e como se alimentam de madeira } \\
\text { acabam se instalando nas peças de madeira e se procriam } \\
\text { gerando novas ninhadas. }\end{array}$ & $\begin{array}{l}\text { Para eliminar os cupins da madeira } \\
\text { seca basta diluir um copo de vinagre com } \\
\text { um copo de água e aplicar na peça de } \\
\text { madeira com um borrifador, até que os } \\
\text { cupins desapareçam. }\end{array}$ \\
\hline Tendência & Gravidade $\quad$ Pontuação \\
\hline 5 & 100 \\
\hline
\end{tabular}

Fonte: Autores (2018).

A Tabela 6 indicou a pontuação de 100, pois não coloca a vida dos alunos e funcionários diretamente em risco,porém é uma patologia grave, pois as ações dos cupins podem levar ao rompimento das peças de madeira e como resultado o desabamento da cobertura. 


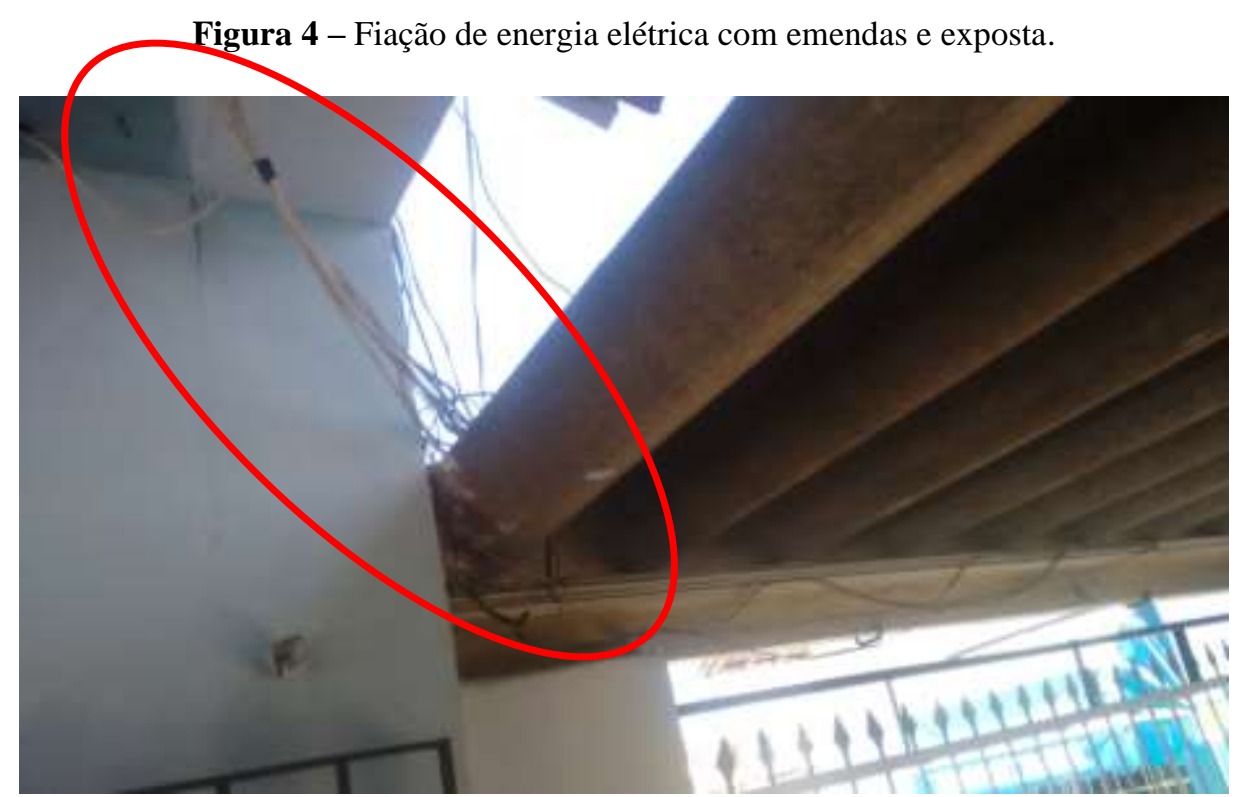

Fonte: Autores (2018)

A Figura 4 mostra fiações de energia elétrica, com emendas realizadas de maneira incorreta e expostas no corredor do pátio da escola

Tabela 7 - Avaliação da Fiação de energia elétrica com emendas realizadas de maneira incorreta e sem eletrodutos.

\begin{tabular}{cccc}
\hline \multicolumn{2}{l}{ Justificativa da ocorrência } & Orientação técnica \\
\hline Falha na execução. & $\begin{array}{c}\text { Refazer as instalações elétricas utilizando } \\
\text { eletrodutos e fazer emendas da maneira } \\
\text { correta. }\end{array}$ \\
\hline Urgência & Tendência & Gravidade & Pontuação \\
\hline 5 & 5 & 5 & 125 \\
\hline
\end{tabular}

Fonte: Autores (2018).

A Tabela 7 indicou a pontuação máxima, pois não coloca a vida dos alunos e funcionários diretamente em risco, devido a possíveis incêndios ocasionados por curtos-circuitos.

Tabela 8 - Ordem de prioridade de Intervenção.

\begin{tabular}{ccc}
\hline Prioridade de Intervenção & Manifestação Patologia & Pontuação \\
\hline $\mathbf{1}^{\mathbf{0}}$ & Rachadura no pilar e na viga & 125 \\
\hline $\mathbf{2}^{\mathbf{o}}$ & Fiação de energia elétrica exposta e com & 125 \\
& emendas & \\
\hline $\mathbf{3}^{\mathbf{0}}$ & Rachadura no muro e no pilar & 125 \\
\hline $\mathbf{4}^{\mathbf{0}}$ & Cupim nas peças de madeira da cobertura & 100 \\
\hline
\end{tabular}

Fonte: Autores (2018)

Por fim, a Tabela 8 indica a ordem de intervenção das patologias verificadas, de acordo com o método GUT, para a intervenção da edificação . 


\section{Conclusão}

A Escola Estadual Professor Rafael Magalhães foi fundada no dia 05 de setembro de 1946 e desde então foram feitas apenas pequenas reformas. Esta constatação de fato justifica as condições verificadas nas instalações prediais da mesma, que cujas manifestações patológicas aparentam ser bem antigas e que não houve uma manutenção recente ou nunca houve manutenção. Mediante esses fatos e por se tratar de uma edificação de gestão pública de ensino existe a necessidade urgente de manutenção da estrutura, pois as manifestações patológicas com a pontuação máxima na tabela de prioridades de intervenção oferecem risco eminente para as pessoas que convivem na edificação, e também para que as patologias e manifestações patológicas não se agravem.

Através da inspeção predial que foi realizada, constatou-se que as manifestações patológicas com maior pontuação na tabela de prioridade de intervenção são originadas por erros construtivos e a falta de manutenção da estrutura.

Considerando o curto tempo para realização desta pesquisa, consideram-se como sugestões para trabalhos futuros a análise de viabilidade de reforma na Escola Estadual Professor Rafael Magalhães, bem como a realização de estudos em outras edificações em âmbito municipal, estadual e nacional.

\section{Referências}

ABNT. (2013). - Associação Brasileira de Normas Técnicas. NBR 15575. Norma Brasileira de Desempenho.

ABNT. (1999) - Associação Brasileira de Normas Técnicas. NBR 5674/1999 - Norma Brasileira de Manutenção de edifícios.

ABNT. (1994) - Associação Brasileira de Normas Técnicas. NBR 5462. Norma Brasileira de Confiabilidade e Mantenabilidade.

Almeida, R. (2008). Manifestações Patológicas em Prédio Escolar: uma análise qualitativa e quantitativa. (Dissertação de Mestrado). Mestrado em Engenharia Civil, Programa de Pós Graduação em Engenharia Civil.Universidade Federal de Santa Maria, Santa Maria, Rio Grande do Sul,Brasil.

Alves, L. G., Thomé, V. M., \& Tosta, J. P. (2017). Manifestações patológicas em casas populares: uma análise de custo. Revista Estudo \& Debate, 24(2).

Ambrosio, T. S. (2004). Patologia, tratamento e reforço de estruturas de concreto no metrô de São Paulo.Trabalho de conclusão de curso (Graduação em Engenharia Civil) - Universidade Anhembi Morumbi, São Paulo, 2004. 128 p.

Azevedo, S. L., \& Guerra, F. L. (2009). Considerações sobre patologias e restauração de edifícios. Téchne, 144.

Cunha, A. J. P., Lima, N. A., \& Souza, V. C. M. (1996). Acidentes estruturais na construção civil. Pini.

Dagostin, G. D. O. (2010). Inspeção Predial do Pavilhão B do Shopping Pórtico de Criciúma-SC. Trabalho de conclusão de curso (Graduação em Engenharia Civil). Universidade do Extremo Sul Catarinense. Criciúma.

Degussa (2003). Manual de Reparo, Proteção e Reforço de Estruturas de Concreto. Ed. Red. Rehabilitar.

França, A. A. V. et al.(2011) Patologia das construções: uma especialidade na engenharia civil. Téchne, 19(174), 72-77.

Helene, P. R. D. L.(2003). Manual para reparo, reforco e protecao de estruturas de concreto. red rehabilitar.

IBAPE. (2012). Instituto brasileiro de avaliações e pericias de engenharia. Norma de inspeção predial nacional. Bela Vista.

Lima, P. R. B. (2005). Consideração do projeto no desempenho dos sistemas construtivos e qualidade da edificação - Proposição de um modelo de banco de dados. (Dissertação de mestrado) Mestrado em Engenharia de Estruturas. Universidade Federal de Minas Gerais.

Pina, G. L. (2013). Patologia nas habitações populares. (Monografia), Graduação em Engenharia Civil, Universidade Federal do Rio de Janeiro.

Rios, F. R. A et al.(2019) Manifestações Patológicas Construtivas em Edificações no Centro de Campina Grande-PB. Revista Eletrônica de Ciências, 18(28), 29.

Souza, V. C. M. D., \& Ripper, T. (1998).Patologia,reforço e recuperação de estruturas de concreto. PINI.

Silva, F. B. D.(2011). Patologia das construções: uma especialidade na engenharia civil. Téchne, 174.

Tutikian, B., \& Pacheco, M.(2013). Inspeção, Diagnóstico e Prognóstico na Construção Civil. Alconpat Internacional. Boletim Técnico $n^{o}$ 01. Março. Unisinos, Brasil.

Torres, A. S., \& Silva, J.(2015). Patologias nos sistemas construtivos das edificações do início do século XX no sul do Rio Grande do Sul-estudo de caso de residencia na cidade de Rio Grande/RS. REEC-Revista Eletrônica de Engenharia Civil, 10(2), 
Research, Society and Development, v. 10, n. 5, e38310514473, 2021

(CC BY 4.0) | ISSN 2525-3409 | DOI: http://dx.doi.org/10.33448/rsd-v10i5.14473

Vieira, M. A.(2016). Patologias Construtivas: Conceito, Origens e Método de Tratamento. Revista Especialize On-line. Goiânia, 12(1).. 